Article

\title{
Assessing the Economic Costs of Sea Level Rise and Benefits of Coastal Protection: A Spatiotemporal Approach
}

\author{
Xinyu Fu ${ }^{1}$ (D) and Jie Song ${ }^{2, *}$ \\ 1 Urban and Regional Planning, College of Design, Construction, and Planning, University of Florida, \\ Gainesville, FL 32611, USA; xinyufu@ufl.edu \\ 2 College of Architecture and Urban Planning, Chongqing University, Chongqing 400044, China \\ * Correspondence: songjay8@gmail.com
}

Received: 19 July 2017; Accepted: 20 August 2017; Published: 22 August 2017

\begin{abstract}
Sea level rise (SLR) is believed to be the most dangerous impact of climate change in coastal regions. Adapting to its impacts has become imperative since SLR is now considered inevitable. Lack of local economic analysis of SLR impacts is one of the major obstacles impeding adaptation. To address this gap, this study employs a spatiotemporal approach to estimate the economic costs of future SLR as well as the benefits of coastal protection, a principal adaptation strategy, under four local SLR projection scenarios in the mainland Miami-Dade County, Florida. Our findings indicate that SLR impacts are nonlinear and coastal protection, while costly, can significantly reduce future potential losses. A novel spatial fishnet approach is also proposed to help local decision makers identify areas that should be prioritized for protection. Findings of this study aim to support local adaptation planning, and call for integrating adaptation for SLR and its uncertainties into local planning frameworks to achieve long-term sustainability and well-being of our precious coastal communities.
\end{abstract}

Keywords: sea level rise; adaptation planning; coastal protection; economic analysis

\section{Introduction}

The coast is on the frontier of natural and anthropogenic stressors [1]. Coastal regions are exceptionally sensitive because of their densely populated and highly developed characteristics [2]. As a result, impacts of climatic variations are usually the greatest along the coast [3]. Additionally, climate change impacts, especially sea level rise (SLR), add another layer of intensity to these already highly exposed areas [4]. Coastal regions and their managers therefore face escalating challenges in safely accommodating growth and development [5].

Adaptation has now been advocated as a primary response to SLR impacts [6-8]. It is because mitigation, while equally important, cannot slow SLR immediately. And, adapting to its impacts has become inevitable, especially at the local community level. Unlike mitigation that requires global action, adaptation is place-based and will maximize the benefits by addressing local needs. In general, there are three major types of adaptation in response to SLR, including protection, accommodation, and retreat [7]. Because it is very costly for urban areas to retreat from already highly developed coastlines, protection and accommodation are now usually the preferred options. Unlike protection and retreat that are considered mutually exclusive, protection and accommodation can be implemented together to greatly reduce the potential risk and vulnerability due to future SLR. Although accommodation is an important adaptation action, protection is still deemed the most essential and necessary adaptation strategy in coastal areas [7,9]. This study focuses primarily on the coastal protection (i.e., seawall) and the costs are believed to be quite expensive, yet less costly 
compared to future losses in the long term [6], but it requires forward thinking and early investments in an issue less urgent compared to many local competing planning agendas. Therefore, adaptation progress has been found delayed due to various constraints $[10,11]$.

Lack of local analysis is one of the principal obstacles. Recent studies that evaluated adaptation planning efforts in the US cities reinforced such recognized constraint and questioned adaptation implementation [12,13]. The absence of practical tools to analyze SLR impacts are believed to significantly hinder local adaptation decisions. Particularly, those that estimate the economic losses from SLR at the community levels are scarce. Previous literature on estimating the economic cost of SLR are primarily macro in form, focusing on the regional or even larger scales [14-16]. Although macro-level SLR impact studies are valuable in supporting higher-level decision making, to facilitate local adaptation planning requires viable cost-effective tools at the disposal of coastal planners on a compatible spatial level [17]. In addition, previous studies often chose several integral SLR scenarios to estimate respective impacts (e.g., $[18,19])$ while ignoring that SLR is a continuous nonlinear process. As adaptation needs to compete for the limited local resources, identifying where adaptation should be prioritized provides important practical meanings. To address these gaps, this paper aims to conduct a case study by employing a spatiotemporal approach to analyze the economic impacts due to future SLR and a spatial fishnet method to identify areas that should be prioritized for adaptation actions. The methods as well as the findings of this research can be generalized to other coastal communities to assist adaptation planning. Thus, coastal planners and managers who are concerned with SLR impacts would find this study useful in guiding local long-range adaptation planning.

\section{Study Area}

We chose Miami-Dade County in Florida (see Figure 1) as our target research area for numerous reasons. In general, coastal regions in the State of Florida are highly vulnerable to SLR due to its long shorelines, low plain elevation, and highly concentrated population and development along its coastline $[20,21]$. This is especially true for the Miami-Dade County, where one of the most populated cities, Miami, is situated. Also, Miami-Dade County has more people below 4-foot above high tide than any state, except Florida and Louisiana, in the US [22]. Miami also ranked first in asset exposure and the ninth in population exposure to climate extremes among world port cities [23]. The Miami area has now become the hot spot for SLR studies because it is considered to be "ground zero" to SLR impacts. In fact, Miami has already been seriously impacted by SLR. Frequent flood events that occurred on a sunny day during high tide conditions, often referred to as the "King tides" or "lunar flooding", have caused serious interruptions to residents and businesses. The impacts of coastal flooding will become even worse with the rising sea in the future [24]. In sum, Miami-Dade County is a very suitable demonstration case area for this research.

In this study, we considered the mainland Miami for its continuous coastline, because a large portion of the north Miami-Dade County is unincorporated areas with tropical wetlands and marshes and, therefore, they have been excluded. We only focused on the coastal protection for urban areas and did not account for environmental costs such as wetland gains and losses. Figure 1 illustrates the final area of interest in this study, which covers all the connected incorporated municipalities along the coastline. 


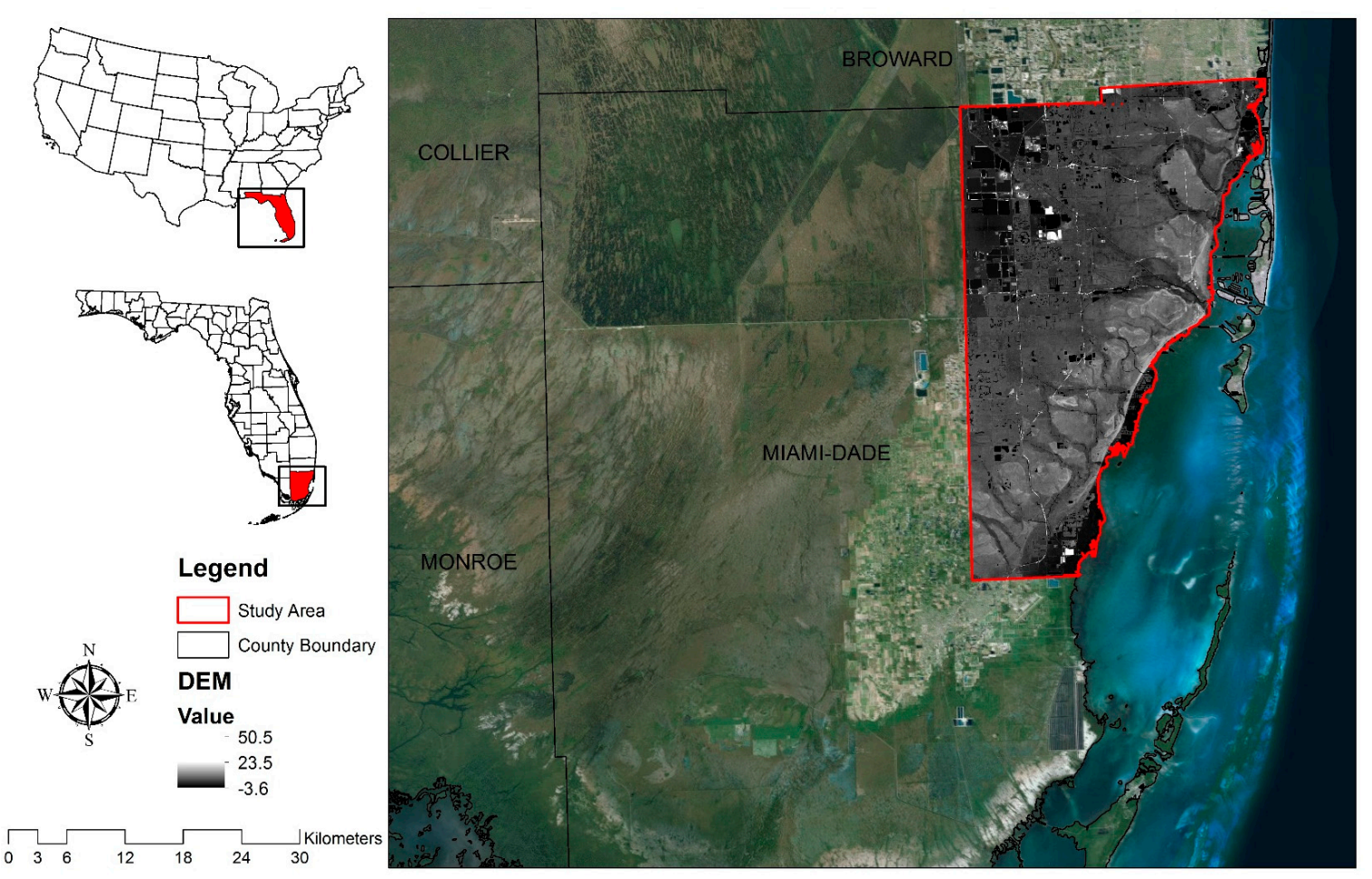

Figure 1. Area of research interest.

\section{Method}

The spatiotemporal approach in this study consists of two analyses. The first is a spatial model that utilizes a high-definition digital elevation model (DEM) derived from the light detection and raging (LIDAR) method to delineate future potential SLR inundation areas. The resulting maps are then overlaid with local parcel information to estimate the potential economic losses due. The temporal analysis aims to link the extent of SLR to its time of occurrence. By coupling two analyses together, this spatiotemporal approach could conduct potential damage assessments due to SLR at a specific point in time. Eventually, adaptation costs will be estimated, and together with the spatiotemporal information, we can further conduct a cost-benefit analysis. The following sections will elaborate each step in this study.

\subsection{Spatial Analysis}

We employed the modified "bathtub" model with local DEM to delineate future SLR inundation areas. Compared with the traditional "bathtub" model that assumes land elevation below projected sea levels will be inundated, the modified model accounts for hydrological connectivity (HC), which can exclude inundation area disconnected from open water [25]. As illustrated in Figure 2, there are generally two types of HC: the "four-sided" and "eight-sided" rules. The "four-sided" rule assumes a grid cell in the DEM is hydrologically connected if any of its cardinal directions are connected to a flooded cell, while the "eight-sided" rule assumes connectivity on both cardinal and diagonal directions. The former rule may have the potential to underestimate SLR impacts, while the latter may have the potential to overestimate [25]. We chose the "eight-sided" rule simply because for planning purposes overestimation is usually more acceptable. 


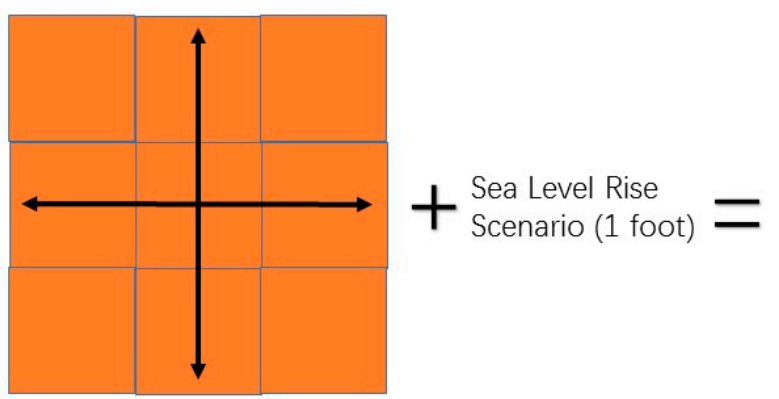

Four-Sided

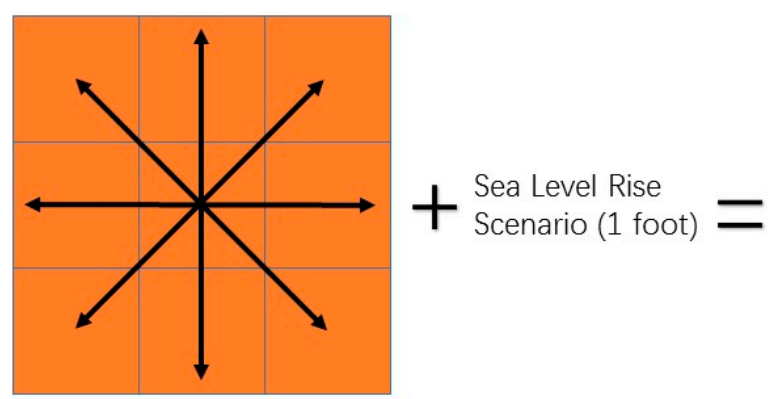

Eight-Sided

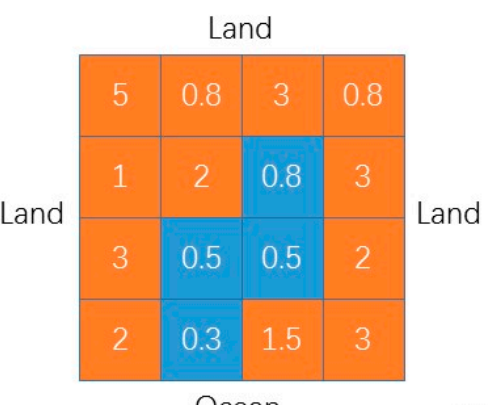

Hydrologic Disconnected
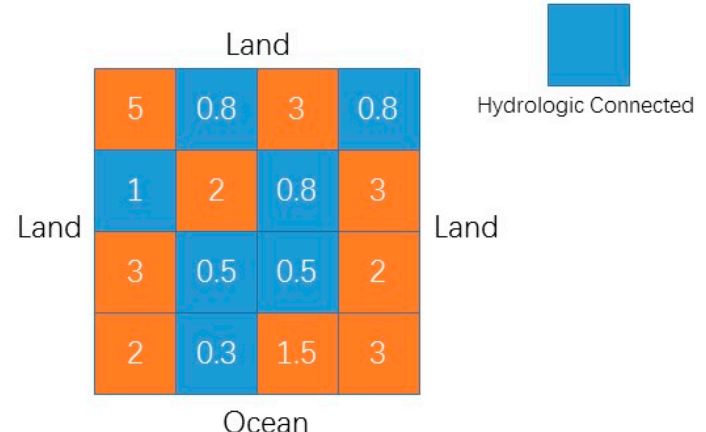

Figure 2. Hydrologic connectivity: four- and eight-sided rule.

The 5-m DEM was retrieved from National Oceanic and Atmospheric Administration (NOAA) Office of Coastal Management (Sea Level Rise Viewer: https://coast.noaa.gov/slr/) for the study area. The DEM is vertically referenced to the North American Vertical Datum of 1988 (NAVD88) with units of meters, to which the projected SLR would also be referenced. The tide epoch for the Miami area was collected from the closest tide station (Station 8723214, Virginia Key, FL, USA) from NOAA (https:/ / tidesandcurrents.noaa.gov). The current tidal epoch is observed over a 19-year period from 1983 to 2015. We chose the Mean Higher High Water (MHHW) levels as the base tidal surface on which future SLR would be added for inundation mapping because MHHW was preferred for areas like Miami that experienced semidiurnal tides during lunar days [19]. The MHHW for this epoch is 0.22 feet $(0.067056 \mathrm{~m})$ above NAVD88. The project year for this study was set to 2015, which was the year of parcel valuation data. To capture the continuity of future SLR, an increment of 0.05 feet $(0.01524 \mathrm{~m})$ was added to the baseline tide surface for each SLR scenario up to 6 feet $(1.8288 \mathrm{~m})$. In total, besides the inundation map for the baseline surface, 120 SLR inundation maps were generated. All mapping processes were accomplished in the geoprocessing environment of ESRI's ArcGIS 10.4 with Python scripts for looping.

Local parcel data with property assessed valuation information for 2015 was collected from the Miami-Dade County GIS Data Service. After the SLR inundation modeling, the resulting maps were then overlaid with the parcel data to identify properties and areas that would be inundated under specific SLR scenarios. Parcels with their geometric centroid points inside the inundation areas would be assumed total losses of both their land and structure assessed values. Although this is a relatively simple assumption, it makes rational sense for planning purposes because if a parcel is repetitively flooded, its total value will be considered for cost-benefit analysis.

\subsection{Temporal Analysis}

Because there exists no consensus on future sea level projections, coastal managers and planners are facing increasing challenges to amend their decision-making frameworks towards forward-thinking and proactive adaptation planning. Existing uncertainties of future SLR are largely due to the unpredictable future emission scenarios which affect the prediction of global temperature change and, particularly, difficulties in projecting ice mass loss from the Greenland and Antarctica ice sheets [26]. Unlike most 
planning literature that considered only one or two SLR scenarios at a specific year in the future, such as 0.5-m SLR in 2080 (i.e., [27]), this study employed several SLR projections as suggested by the local leading climate change taskforce [28]. Although local decision makers often prefer one single conclusion, given the existing uncertainty of future SLR, multiple possible future SLR storylines must be considered [17]. SLR projection models in this study include NOAA High Curve [29], USACE High Curve [30], IPCC AR5 RCP 8.5 Median Curve [31], and NOAA Intermediate Low/USACE Low Curve [29,30]. All the SLR projection models share an identical function as below and illustrated in Figure 3. Their projection values vary due to the distinct parameters of future acceleration of sea level change.

$$
\Delta \mathrm{E}=\mathrm{E}\left(\Delta \mathrm{T}_{1}\right)-\mathrm{E}\left(\Delta \mathrm{T}_{2}\right)=\alpha\left(\Delta \mathrm{T}_{1}-\Delta \mathrm{T}_{2}\right)+\beta\left(\Delta \mathrm{T}_{1}^{2}-\Delta \mathrm{T}_{2}^{2}\right)
$$

where $\Delta \mathrm{E}$ is eustatic sea level change (in meters) compared to the project beginning year (i.e., 2015 in this study), to which future SLR is referenced. $\Delta \mathrm{T}_{1}$ is the time difference between projection year and reference year 1992. $\Delta \mathrm{T}_{2}$ is the time difference between project year and reference year 1992. $\alpha$ is the rate of local mean sea level change, which is a constant equal to 0.00239 (meter per year) based on the relative sea level trend in Miami from NOAA (http: / tidesandcurrents.noaa.gov/). $\beta$ represents the acceleration of global sea level change and it varies under different SLR projections. $\beta$ equals to $1.56 \times 10^{-4}$ for NOAA High, $1.13 \times 10^{-4}$ for USACE High, $4.684499 \times 10^{-5}$ for IPCC AR5 RCP8.5 Median, and $2.71262 \times 10^{-5}$ for NOAA Intermediate Low/USACE Low.

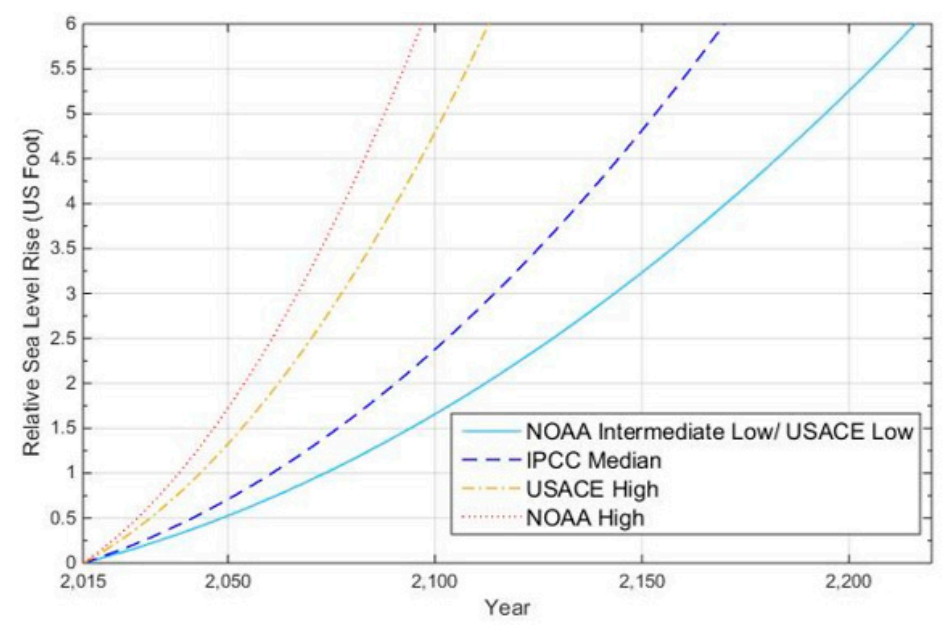

\begin{tabular}{|c|c|c|c|c|}
\hline $\begin{array}{c}\text { SLR (US } \\
\text { Foot) }\end{array}$ & Low & $\begin{array}{c}\text { IPCC } \\
\text { Median }\end{array}$ & $\begin{array}{c}\text { USACE } \\
\text { High }\end{array}$ & $\begin{array}{c}\text { NOAA } \\
\text { High }\end{array}$ \\
\hline 1 & 2073 & 2061 & 2043 & 2038 \\
\hline 2 & 2112 & 2090 & 2062 & 2054 \\
\hline 3 & 2143 & 2114 & 2077 & 2067 \\
\hline 4 & 2170 & 2135 & 2091 & 2078 \\
\hline 5 & 2194 & 2153 & 2102 & 2088 \\
\hline 6 & 2216 & 2170 & 2113 & 2097 \\
\hline
\end{tabular}

Figure 3. Sea level projections for Miami-Dade County (table on the right indicates the specific year that certain SLR integral scenario will occur based on different projection models).

\subsection{Economic Analysis}

We assume the coastal protection in this study is provided by building additional seawalls. Although no single adaptation strategy will be sufficient for future SLR, hard engineering protection remains the most essential strategy to prevent inland flooding. We utilized the cost estimation function from [6], in which seawall costs were computed by multiplying seawall length, height, and unit costs. This function assumes "a brick is a brick" so that the costs of seawall are linear both in its length and height. The length of the coastline was calculated in ArcGIS, and the seawall length was then calculated by multiplying coastline length by a ratio of protection level, $\mathrm{L}$ (i.e., protection ratio $\mathrm{L}$ is between 0 and 1 , where 0 indicates no protection and 1 indicates full protection). The height of the seawall to be finally built at a future year is equal to the sum of MHHW and SLR in that year to prevent coastal flooding. As the unit cost of seawall varies significantly, this study employed the unit cost estimate (i.e., $\$ 688.85$ per foot in 1993 dollars) from [32] and adjusted it in 2015 dollars (i.e., $\$ 1129.89$ per foot). We also considered the annual maintenance costs of seawalls to be 1 percent of annum capital costs of seawall [33]. Annual protection 
costs were calculated below by equation 2 , which assumed that the construction costs stayed constant over time. Because the technology for building seawalls is considered very mature, its associated costs will not change much in the future [34]. For simplicity, the project start year was assumed to be 2015 because when future adaptation actions would take place cannot be estimated.

$$
\mathrm{PC}_{\mathrm{S}, \mathrm{T}}^{\mathrm{AN}}=\frac{\mathrm{U} \times \mathrm{L} \times 1 \times(\mathrm{S}+\mathrm{MHHW})}{\mathrm{T}} \times(101 \%)
$$

where $S$ is the SLR scenario and T is its projection year, which varies based on different SLR projection scenarios. $U$ is the unit cost of building seawalls. $L$ is the coastal protection ratio, while 1 represents the total length of the coastline.

To conduct a cost-benefit analysis of adaptation decisions, we need to calculate both the net present value of economic losses and protection costs due to future SLR. To this end, we need to assume that land and property values will rise at the same rate of per capita income growth in Miami-Dade County and a discounting rate lies $1 \%$ above the growth rate [34]. Net present value of economic capital losses CL was calculated by Equation (3) below. Because of the assumption of constant costs of building seawalls, net present values of protection costs PC were therefore calculated only by discounting (see Equation (4)).

$$
\begin{gathered}
\mathrm{CL}_{\mathrm{S}, \mathrm{T}}^{\mathrm{NPV}}=\sum_{\mathrm{s} \in \mathrm{S}, \mathrm{t} \in \mathrm{T}} \Delta \mathrm{CL}_{\mathrm{s}} \times\left(\frac{1+\mathrm{g}}{1+\mathrm{r}}\right)^{\mathrm{t}} \\
\mathrm{PC}_{\mathrm{S}, \mathrm{T}}^{\mathrm{NPV}}=\sum_{\mathrm{t}=0}^{\mathrm{T}} \mathrm{PC}_{\mathrm{S}, \mathrm{T}}^{\mathrm{AN}} \times\left(\frac{1}{1+\mathrm{r}}\right)^{\mathrm{t}}
\end{gathered}
$$

where $S$ and $T$ are the same as they are in Equation (1). $\Delta C L$ s is the increased economic capital losses due to SLR between two incremental SLR scenarios. For example, the increased economic losses of 0.1 -foot SLR and 0.15-foot SLR are $\$ 68.3$ and $\$ 70.0$ million, respectively, so that the increased economic losses of $\triangle C L$ for the 0.05 -foot SLR change equal to $\$ 0.7$ million. $g$ is the growth rate (i.e., $4.1 \%$ according to [35]. $r$ denotes the discounting rate (i.e., 5.1\%).

Coastal decision makers are generally reluctant to invest in building seawalls early when the SLR impacts are still minimal, and building early will induce more costs due to the aggregated annual maintenance costs. While on the other hand, they are also against building the seawalls too late when SLR impacts become too significant. Although this study is not intended to find the tipping point for such adaptation decision to be made, to provide valuable information for coastal managers to help their adaptation decision making, we will first conduct the cost-benefit analysis to identify at what level of SLR and when the costs of adaptation (i.e., protection in this study) will exceed the costs of economic capital losses due to future SLR under the four different SLR projection scenarios. To begin with, we assume that the whole coastline will eventually be protected. It is a rational assumption because the selected study region of the mainland Miami-Dade County is highly developed, and retreat is believed to be an implausible option.

Besides full protection, the optimal protection ratio (OPR) is also considered in many studies by assuming that the land will be protected when benefits (i.e., avoided losses) exceed costs of protection $[6,8,36,37]$.

When computing OPR, because such studies are usually focusing on large scales, they assume a hypothetical function between protection and avoided losses, and derive the Equation (5) to calculate the OPR. The OPR that is calculated by the following hypothetical function is referred to as the assumed OPR afterward.

$$
\mathrm{L}^{*}=\operatorname{Max}\left\{0,1-\frac{\mathrm{PC}_{\mathrm{S}, \mathrm{T}}^{\mathrm{NPV}}}{2 \times \mathrm{CL}_{\mathrm{S}, \mathrm{T}}^{\mathrm{NPV}}}\right\}
$$

Although this hypothetical approach provides an approximate estimate of how much of the coastline should be protected, it lacks the spatial information on where the coastline should be 
protected. Thus, we divide the coastlines into 100 segments and overlay each segment with the land DEM to simulate SLR impacts under different scenarios. In this way, we could analyze each of the coastal segments and calculate the protection costs and potential losses for that specific coastal segment by assuming others are being fully protected. By using this spatial fishnet approach, we could estimate the OPR, referred to as the estimate OPR afterward, more accurately without basing on any hypothetical relationship between the protection costs and avoided losses like the assumed OPR approach. In addition, we could derive important spatial information on which parts of the coastline should be protected. Finally, this estimated OPR will be compared with the assumed or hypothetical OPR calculated by equation 5 to find out whether previous studies' assumption on the relationship between protection and avoided losses stands.

\section{Results and Discussion}

Inundation processes and impacts are obviously nonlinear (see Figure 4) with slight increases at the beginning, and speeding up exponentially after reaching one or several thresholds, which is consistent with a previous study in south Florida [38]. Such nonlinear processes are largely due to local topography, and the inundation processes may vary in other regions. The number of inundated parcels almost doubled from 627 at 1.75-foot SLR to 1244 at 1.8-foot SLR, which is an increase of 617, or $98 \%$. Other jumps from the number of inundated parcels due to future SLR are from 1.95-foot to 2.00 -foot SLR (685 in number increases and 49\% in percentage change) and from 2.20-foot to 2.25-foot SLR (1515 of number increases and 68\% in percentage change). After 3.55-foot SLR, every 0.05 foot of additional SLR will potentially induce more than 1000 number of parcels to be inundated. The total values of potential inundation costs are consistent with the pattern of the number of parcels that will be inundated due to future SLR. The greatest jump of cumulative parcel values in percentage change is from 2.2-foot to 2.25-foot SLR (i.e., 79.2\% change). Based on both the changes in numbers of parcels and inundation costs due to future SLR, the threshold from which SLR impacts intensify dramatically is at approximately 2.2-foot SLR for all SLR scenarios.

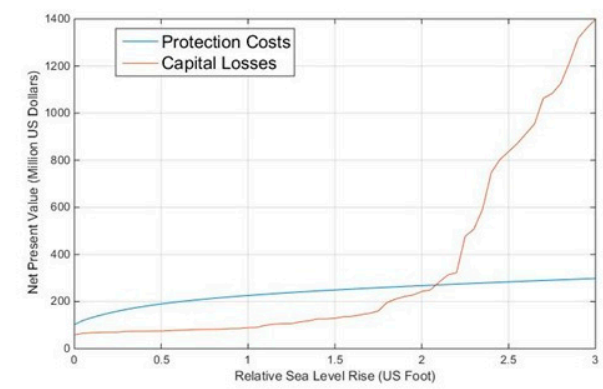

(a)

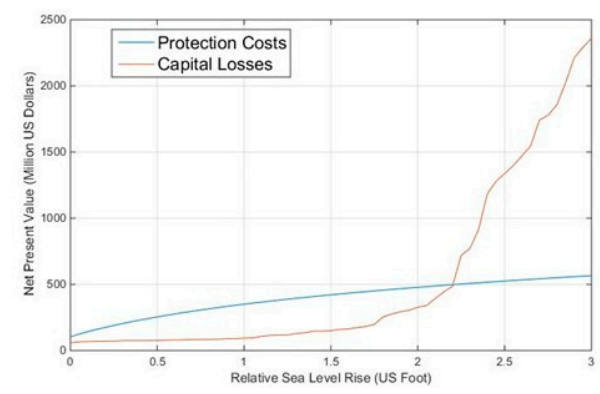

(c)

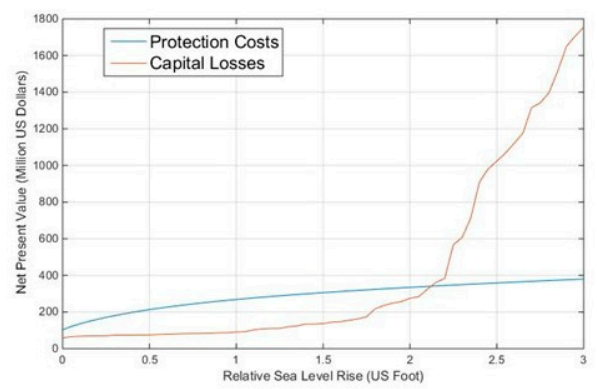

(b)

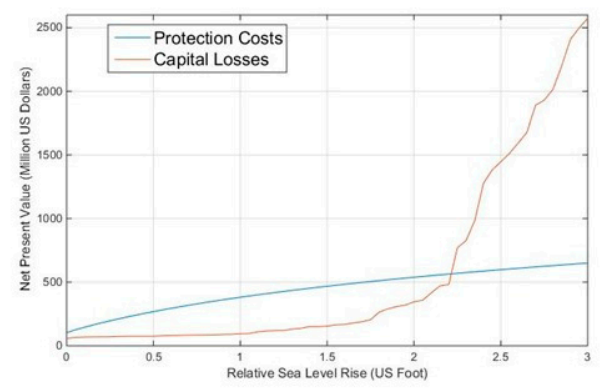

(d)

Figure 4. Net present values of protection costs and potential losses under different sea level rise scenarios. (a) NOAA Intermediate Low/ USACE Low; (b) IPCC Median; (c) USACE High; (d) NOAA High. 
Because in which future year SLR will reach a certain threshold of inundation costs varies significantly across all four SLR projections, the year that avoided damages exceeding adaptation costs will also be different. The cost-benefit ratios of different SLR scenarios share similar pictures with their respective economic losses lines. After the cost-benefit threshold (CBT), the cost-benefit ratios increase rapidly and reaches the maximum at the highest SLR scenario (i.e., 6 feet) considered in this study. The cost-benefit ratios when SLR reach 6 feet are 33.5, 37.5, 38.6, and 37.6 for the Low, IPCC Median, USACE High, and NOAA High SLR scenarios, respectively. In other words, every dollar spent up front for adaptation has the potential in reducing at least 33.5 dollars of potential losses due to inundation when sea level rises to 6 feet, by only considering the potential asset losses.

This study also identifies several critical thresholds for the local SLR inundation impacts, but large uncertainties still exist among the time frames of these thresholds. And, which scenario to choose from is becoming one of the greatest challenges for coastal decision makers. The temporal information associated with the SLR thresholds could help to set local adaptation planning timelines, while they are doubtful to serve as the tipping point of time for action. Adaptation will take place much earlier than SLR reaches any of the thresholds identified in this research. In fact, South Florida has already been seriously affected by SLR impacts during "King Tide" seasons [39]. Local governments and responsible agencies have taken adaptation actions to avoid further losses. For example, City of Miami Beach plans to invest $\$ 500$ million for SLR adaptation. The city has already undertaken several adaptation measures such as improvements of sewer systems to prevent salt water backflow and construction of pump stations to assist in keeping the streets dry.

Since full coastline protection may not be needed immediately, the optimal protection levels are therefore useful in guiding where local adaptation actions for SLR should be prioritized. Both the estimated and assumed optimal protection ratio (OPR) varies under different SLR projections (see Figure 5). However, the variations within the estimated or assumed OPR are comparably small across the four SLR projection scenarios. They generally share similar patterns in no or low protection at the lower end of the SLR scenarios for the assumed and estimated OPR respectively, and after certain thresholds, the optimal protection ratios increase rapidly. Both methods in estimating the OPR indicates almost full-coastline protection at the higher end of the SLR scenarios due to the high stake at risk compared to the "low" costs of adaptation. There exist large variations between the two methods of estimating the OPR. Using the hypothetical function underestimates the OPR (i.e., assumed OPR) at the lower end of SLR scenarios and overestimates the OPR in the medium range compared to the estimated OPR by using the spatial fishnet approach. Advantages of using the new method proposed in this study to estimate the OPR are that it not only provides more accurate local estimates, but also provides important spatial information of where adaptation should be prioritized. Because there are minor variations among the different SLR projections in terms of the values of OPR, we chose the IPCC medium scenario to be the example for presentation. Figure 6a illustrates the estimates of potential capital losses of each controlled coastal segment from 0 - to 6 -foot SLR. Figure $6 \mathrm{~b}$ is the cross-sectional view and both figures can demonstrate that different coastal segments vary significantly in terms of potential economic inundation risk due to future SLR. By comparing the estimated costs of protection of each coastal segment to the potential capital losses under different SLR scenarios, where should be prioritized for protection based on the cost-benefit analysis can be obtained (see Figure 7). Through this approach, local planners could decide which parts of the coastline need urgent attention and use such supporting information to guide adaptation actions. 


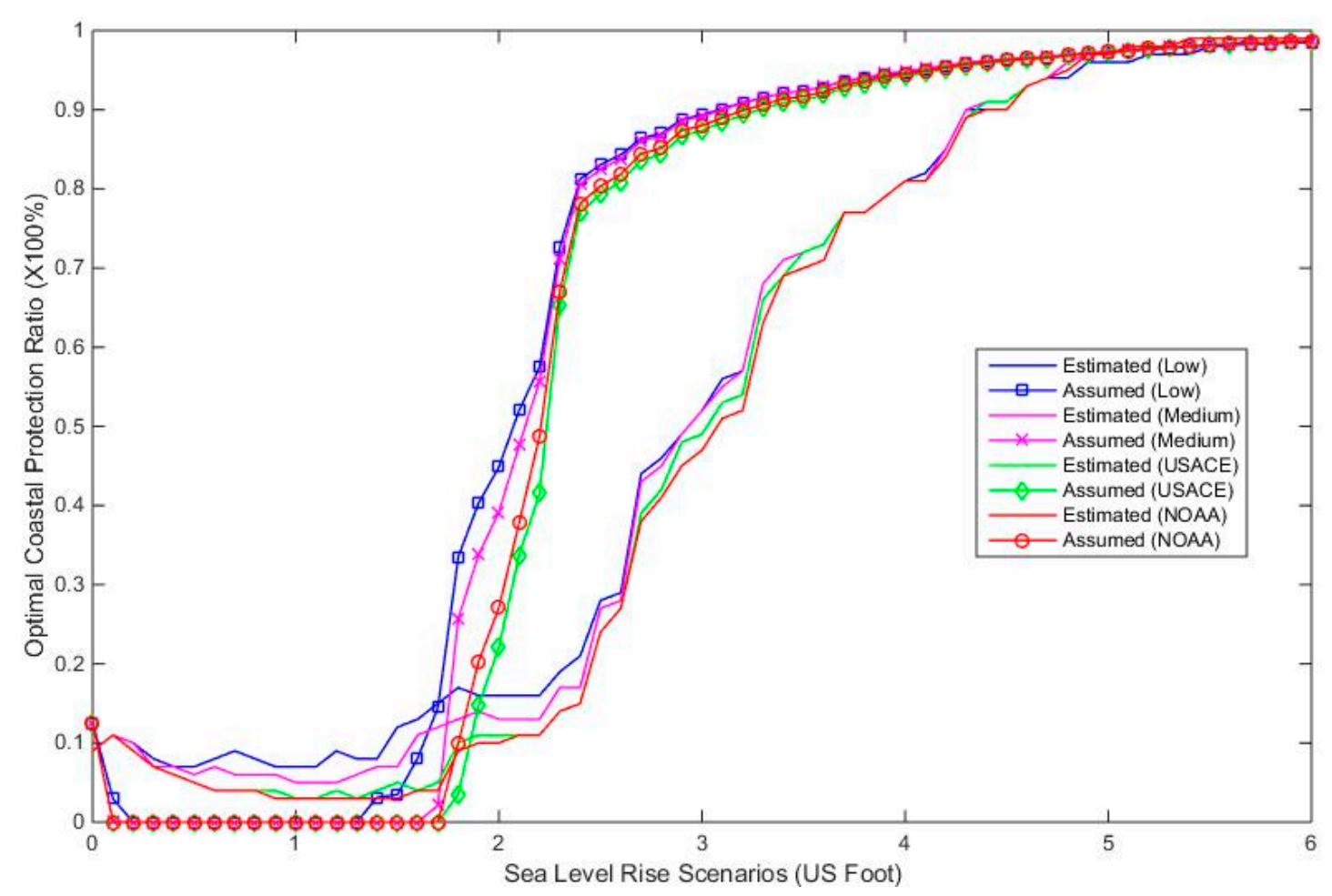

Figure 5. Estimated and assumed OPRs under different sea level rise scenarios.

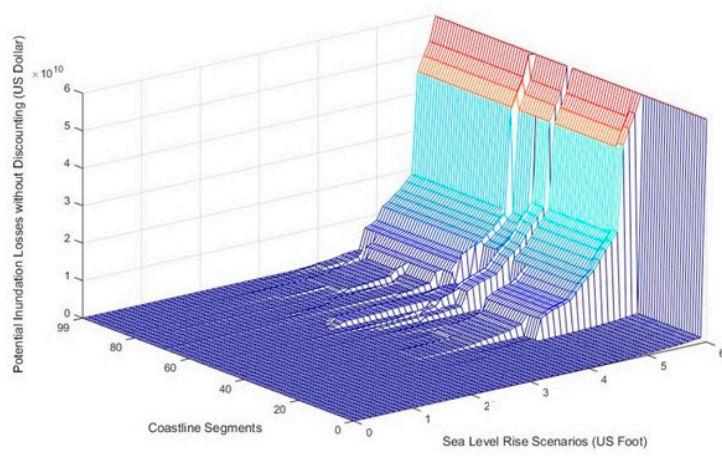

(a)

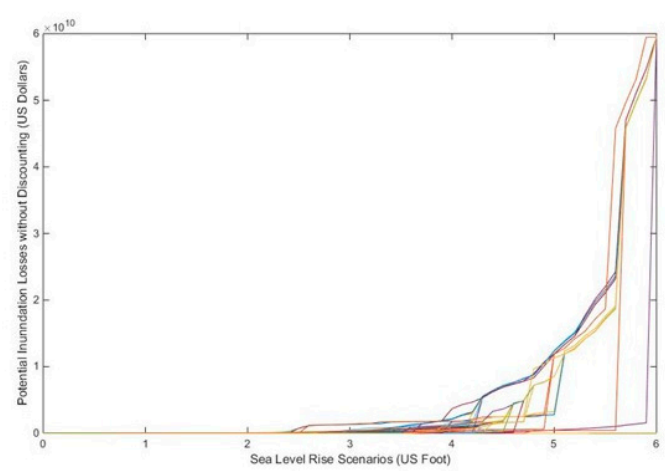

(b)

Figure 6. (a) Potential economic losses for all the divided coastal segments under IPCC Median SLR scenario; (b) cross-sectional view. 

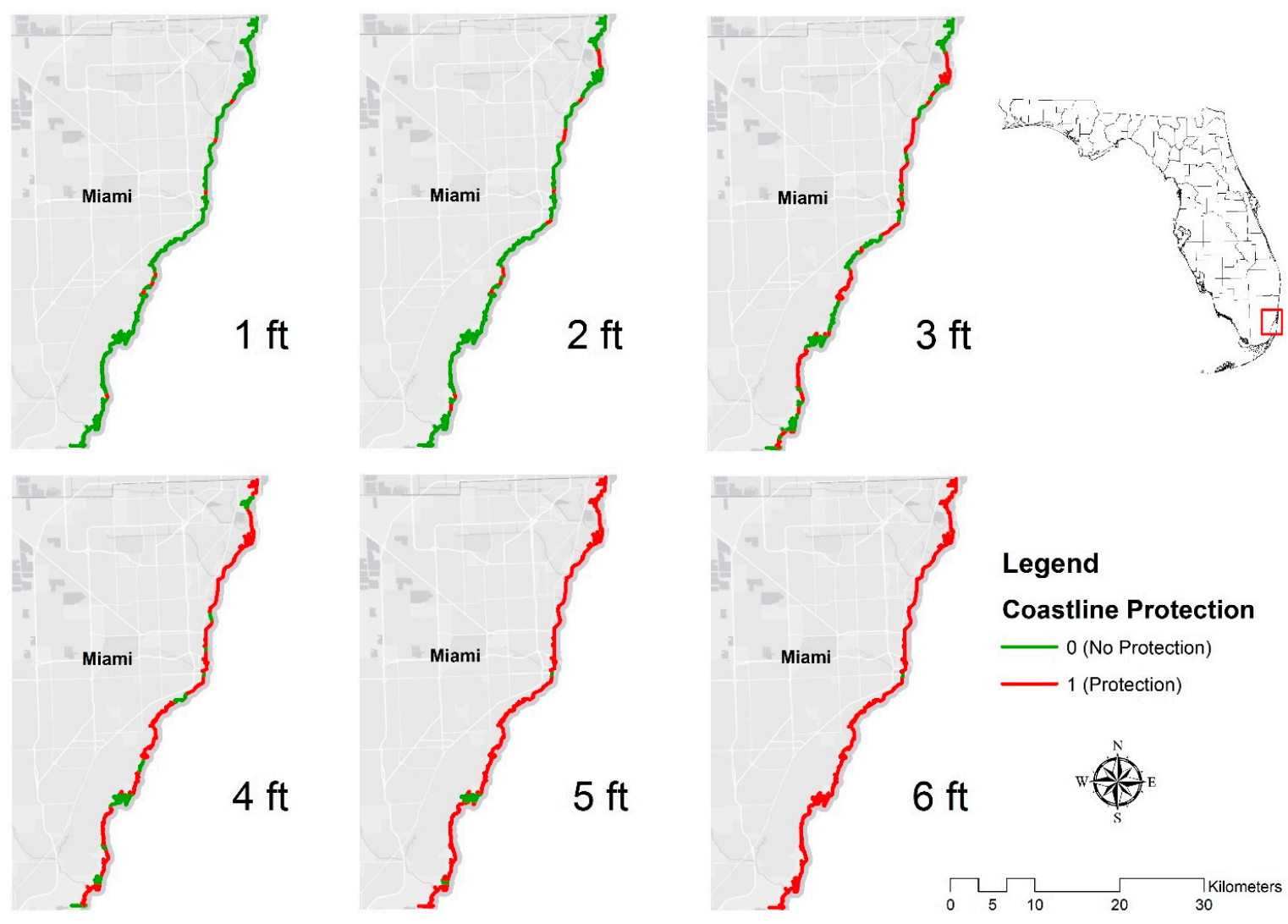

Figure 7. Optimal protection areas.

To date, the underlying uncertainties of future SLR remain unresolved. The wide range between the lower and upper limit for SLR projections has made planning for future SLR highly challengeable for all coastal regions. Although local decision makers often prefer one single future SLR prediction, given the existing science, it is reasonable to think that such precise information will not be available anytime soon. Existing practices of coping with SLR are still largely ad hoc responses, either triggered by devastating coastal hazard events (e.g., Hurricane Katrina at New Orleans, Hurricane Sandy at New York) or by ongoing out-of-control impacts (e.g., "King Tides" in South Florida). Scholars have long advocated for introducing adaptation planning into the long-term urban planning framework while existing adaptation efforts in the US had significant room for improvements $[13,40,41]$. They especially questioned the implementation given such decision making is often difficult, involving a variety of factors including political, social, environmental, economic, and legal. As SLR continues, coastal communities are becoming increasingly vulnerable to climate variations and adaptation actions will need to be implemented at some point in the future. Although adaptation is very costly, considering highly developed coastal areas like Miami, this study found adaptation very cost-effective in the long run, which is consistent with other SLR adaptation literature $[6,7,9]$. Moving towards adaptation is essentially adopting the risk management approach that requires local communities to think in long-term and bear some levels of risk to avoid unnecessary losses due to continuing SLR and to promote sustainable developments.

As coastal managers and planners are increasingly concerned with the issues of SLR, local analysis of SLR impacts will become urgently needed. In fact, many coastal cities and regions have already conducted studies of local vulnerability to potential SLR impacts but the local economic analysis of SLR impacts is still scarce [12,42]. This study provides a novel spatial approach coupled with cost-benefit analysis to identify areas that are the most vulnerable in terms of economic exposure and, therefore, should be prioritized for adaptation. Other coastal communities could easily employ this methodology to generate valuable information of potential SLR impacts to assist local adaptation planning. This 
study also has important planning implications. As far as planning is concerned, climate change and SLR alter the traditional paradigm of planning that assumes a stable coastline and environment. Urban planners now need to worry about increased risk of coastal hazards induced by SLR including flooding, erosion, and saltwater intrusion. Consequently, planning policies such as building codes and land uses will have to be adjusted accordingly to adapt to the changing environment. Results of the study could help coastal planners assess the cost-effectiveness of coastal protection and provide them important information in guiding long-term planning endeavors (e.g., comprehensive planning). By identifying areas that should be prioritized for adaptation, local planners could allocate resources more wisely in communities that are more vulnerable to SLR. By comparing the potential costs of SLR and benefits of adaptation, planners can employ such information to communicate with the public to make decisions on whether local communities are willing to continue to invest in the costly adaptation or to retreat from the coastline and guide developments inland. However, it should also be noted that the cost-benefit approach in this study provides the information of SLR impacts from the economic perspective only. When making adaptation decisions, economic soundness is not the only determining factor and other factors, such as social equity issues, are equally important [43]. Thus, there exists significant room for further research in this field of adaptation planning for climate change and SLR.

\section{Limitations and Future Research}

This research focused on a large metropolitan area that is on the frontier against SLR. Like any other research, this study has its limitations. First, it shares many same limitations of existing SLR studies. These include static inundation and static topography, which assumes coastal land does not change in response to SLR, and SLR will always be gradual and continuous [1]. For example, in areas like Florida that are the hotspots of tropical storms, frequent storm surge events could alter local topography over long periods of time, which simultaneously changes SLR impacts. However, because how future topography will change is now impossible to estimate, we assume no change to local topography throughout the time period of SLR, which is apparently wrong since SLR and other coastal events will certainly affect the topography. In addition, coastal hazards were not considered with SLR impacts as a modest rise in sea levels could tremendously intensify the impacts of these coastal hazards $[27,44]$. Future research should further assess combined impacts by coupling storm surge models and/or flooding modeling with SLR. Also, future population changes and developments were also not factored into this study because they were largely unknown. Future research could conduct analysis based on various growth scenarios.

Second, only taxable properties from the local parcel data were analyzed to estimate the potential inundation losses due to SLR, and such estimates were obviously not exhaustive. Direct impacts on critical infrastructures, such as roads and power plants, were not considered, and indirect impacts, such as momentary losses due to business interruptions, delayed services by public facilities, and potential economic impacts of local tourism, were also not accounted for. However, they could eventually drive local adaptation decisions. To precisely estimate the tipping point of future adaptation actions, a comprehensive impact analysis is necessary. While considering all these impacts due to SLR can hardly be accomplished in one study, future research should build on existing findings and address these gaps.

Third, although the cost-benefit analysis is an important tool to assist local decision making, it alone will not determine the implementation of adaptation strategies. Thus, it is a general limitation for the majority of cost-benefit studies and this study is no exception. Communities may not rely on the cost-benefit analysis to move adaptation implementation forward. As observed in Florida, communities prefer to take low-regret adaptation actions to deal with the already emergent problems associated with SLR [45]. However, information generated by employing the cost-benefit analysis in this study still provides important information for local planners and managers to understand the potential economic costs of SLR and the benefits of adaptation.

Fourth, we only considered one adaptation scenario; building seawalls. Although hard engineering strategies (i.e., building seawalls) are unavoidable in highly developed areas like Miami 
to prevent seawater intrusion, other adaptation actions such as elevating structures and beach nourishment are also necessary. It is simply because no single adaptation solution alone can solve the SLR impacts. Future studies should consider additional adaptation strategies.

Lastly, research limitations also rooted from the spatial methodology of SLR inundation modeling. The accuracy of SLR inundation mapping heavily relies on the resolution of DEM. This study utilized the 5-m high-resolution DEM from NOAA, but vertical and horizontal errors were unavoidable due to data collection and post-processing of LIDAR information [25]. Thus, while higher-resolution DEM leads to more accurate inundation mapping, marginal errors cannot be eliminated. Upon future advancements in remote sensing and data processing, high-resolution raster modeling will delineate SLR inundation areas more accurately and precisely and, therefore, enhance vulnerability analysis and facilitate adaptation decision making. Also, given the porous limestone base of the Miami region, water will potentially rise along with the ocean from underground, and this dynamic is not captured by the existing 'bathtub' model. Future research should enhance the method or utilize other approaches that could account for this dynamic for more accurate results.

\section{Conclusions}

While the large uncertainty of future SLR greatly hinders the progress of adaptation at local levels, understanding the local impacts of SLR by scenario planning and establishing a planning time frame for future SLR become essential steps towards adaptation decisions. As its first attempt, this research integrated spatial, temporal, and cost-benefit analyses together to anticipate future SLR impacts at local levels where adaptation decisions are made. It provides both an adaptation decision-support method and important information of local SLR impacts to coastal managers and planners. They are not only useful in determining the continuous nonlinear impacts of future SLR that existing studies usually neglect, but also they provide local decision makers with temporal and spatial information to support adaptation decision making. The results of this study call for integrating or mainstreaming adaptation into local existing planning frameworks (e.g., comprehensive planning and hazard mitigation planning).

The uncertainties of future SLR is now recognized to be inevitable and local planners must amend their singular traditional paradigm of planning to accommodate multiple scenarios. Such uncertainties of future impacts should be embraced by local decision makers and planners in their short-term and long-term tasks, and they are capable given that many existing planning efforts already involve planning for large uncertainties, such as storm surge modeling and emergency management. As wealthier areas generally adopt higher adaptation standards [6], the choice of scenarios for adaptation action is upon local decision makers. Only when future SLR impacts and their uncertainties are seriously considered will many existing projects be better adapted to such future challenges. Adaptation in such a proactive way is believed to be cost-effective, and only by doing so can we buy more time for the parallel mitigation policies to become effective.

Acknowledgments: The authors are grateful to the University of Florida Graduate Student Fellowship that makes this research possible. The open sources from which the data in this research were collected must be thanked for sharing them for no cost. The publication of this article was funded by the University Florida Open Access Publishing Fund.

Author Contributions: Xinyu Fu and Jie Song made equal contributions to this research. They developed the initial research ideas together. Xinyu Fu initiated the research by collecting data, conducting modeling and statistical analysis, and writing the draft of this paper. Jie Song provided invaluable support on modeling and writing throughout the time of this research. Both authors have made considerable efforts to the revisions of the manuscript.

Conflicts of Interest: The authors declare no conflict of interest.

\section{References}

1. Kirshen, P.; Merrill, S.; Slovinsky, P.; Richardson, N. Simplified method for scenario-based risk assessment adaptation planning in the coastal zone. Clim. Chang. 2012, 113, 919-931. [CrossRef] 
2. National Oceanic and Atmospheric Administration. National Coastal Population Report: Population Trends from 1970 to 2020. 2013. Available online: http:/ / oceanservice.noaa.gov / facts / coastal-population-report. pdf (accessed on 23 November 2016).

3. Kron, W. Coasts: The high-risk areas of the world. Nat. Hazards 2013, 66, 1363-1382. [CrossRef]

4. Storch, H.; Downes, N.K. A scenario-based approach to assess Ho Chi Minh City's urban development strategies against the impact of climate change. Cities 2011, 28, 517-526. [CrossRef]

5. Jabareen, Y. Planning the resilient city: Concepts and strategies for coping with climate change and environmental risk. Cities 2013, 31, 220-229. [CrossRef]

6. Hinkel, J.; Lincke, D.; Vafeidis, A.T.; Perrette, M.; Nicholls, R.J.; Tol, R.S.; Marzeion, B.; Fettweis, X.; Ionescu, C.; Levermann, A. Coastal flood damage and adaptation costs under 21st century sea-level rise. Proc. Natl. Acad. Sci. USA 2014, 111, 3292-3297. [CrossRef] [PubMed]

7. Nicholls, R.J.; Cazenave, A. Sea-level rise and its impact on coastal zones. Science 2010, 328, $1517-1520$. [CrossRef] [PubMed]

8. Tol, R.S. Estimates of the damage costs of climate change. Part 1: Benchmark estimates. Environ. Resour. Econ. 2002, 21, 47-73. [CrossRef]

9. Hallegatte, S.; Green, C.; Nicholls, R.J.; Corfee-Morlot, J. Future flood losses in major coastal cities. Nat. Clim. Chang. 2013, 3, 802-806. [CrossRef]

10. Bedsworth, L.W.; Hanak, E. Adaptation to climate change: A review of challenges and tradeoffs in six areas. J. Am. Plan. Assoc. 2010, 76, 477-495. [CrossRef]

11. Measham, T.G.; Preston, B.L.; Smith, T.F.; Brooke, C.; Gorddard, R.; Withycombe, G.; Morrison, C. Adapting to climate change through local municipal planning: Barriers and challenges. Mitig. Adapt. Strateg. Glob. Chang. 2011, 16, 889-909. [CrossRef]

12. Fu, X.; Song, J.; Sun, B.; Peng, Z.R. Living on the edge: Estimating the economic cost of sea level rise on coastal real estate in the Tampa Bay region, Florida. Ocean Coast. Manag. 2016, 133, 11-17. [CrossRef]

13. Woodruff, S.C.; Stults, M. Numerous strategies but limited implementation guidance in US local adaptation plans. Nat. Clim. Chang. 2016. [CrossRef]

14. Bosello, F.; Roson, R.; Tol, R.S. Economy-wide estimates of the implications of climate change: Sea level rise. Environ. Resour. Econ. 2007, 37, 549-571. [CrossRef]

15. Tebaldi, C.; Strauss, B.H.; Zervas, C.E. Modelling sea level rise impacts on storm surges along US coasts. Environ. Res. Lett. 2012, 7, 014032. [CrossRef]

16. Yohe, G.; Neumann, J.; Marshall, P.; Ameden, H. The economic cost of greenhouse-induced sea-level rise for developed property in the United States. Clim. Chang. 1996, 32, 387-410. [CrossRef]

17. King, P.G.; McGregor, A.R.; Whittet, J.D. Can California coastal managers plan for sea-level rise in a cost-effective way? J. Environ. Plan. Manag. 2016, 59, 98-119. [CrossRef]

18. Heberger, M.; Cooley, H.; Herrera, P.; Gleick, P.H.; Moore, E. Potential impacts of increased coastal flooding in California due to sea-level rise. Clim. Chang. 2011, 109, 229-249. [CrossRef]

19. Cooper, H.M.; Chen, Q.; Fletcher, C.H.; Barbee, M.M. Assessing vulnerability due to sea-level rise in Maui, Hawai 'i using LiDAR remote sensing and GIS. Clim. Chang. 2013, 116, 547-563. [CrossRef]

20. Hauer, M.E.; Evans, J.M.; Mishra, D.R. Millions projected to be at risk from sea-level rise in the continental United States. Nat. Clim. Chang. 2016. [CrossRef]

21. Song, J.; Fu, X.; Gu, Y.; Deng, Y.; Peng, Z.R. An examination of land use impacts of flooding induced by sea level rise. Nat. Hazards Earth Syst. Sci. 2017, 17, 315-334. [CrossRef]

22. Strauss, B. Florida and the Rising Sea. 2012. Available online: http://sealevel.climatecentral.org/news / floria-and-the-rising-sea (accessed on 23 November 2016).

23. Hanson, S.; Nicholls, R.; Ranger, N.; Hallegatte, S.; Corfee-Morlot, J.; Herweijer, C.; Chateau, J. A global ranking of port cities with high exposure to climate extremes. Clim. Chang. 2011, 104, 89-111. [CrossRef]

24. WPBT2. South Florida's Rising Seas—Sea Level Rise Documentary. Available online: https://www.youtube. com/watch?v=-JbzypWJk64 (accessed on 15 June 2017).

25. Poulter, B.; Halpin, P.N. Raster modelling of coastal flooding from sea-level rise. Int. J. Geogr. Inf. Sci. 2008, 22, 167-182. [CrossRef]

26. Jevrejeva, S.; Grinsted, A.; Moore, J.C. Upper limit for sea level projections by 2100. Environ. Res. Lett. 2014, 9, 104008. [CrossRef] 
27. Shepard, C.C.; Agostini, V.N.; Gilmer, B.; Allen, T.; Stone, J.; Brooks, W.; Beck, M.W. Assessing future risk: Quantifying the effects of sea level rise on storm surge risk for the southern shores of Long Island, New York. Nat. Hazards 2012, 60, 727-745. [CrossRef]

28. Southeast Florida Regional Climate Change Compact. Unified Sea Level Rise Projection. 2015. Available online: http:/ / www.southeastfloridaclimatecompact.org/wp-content/uploads/2015/10/2015-CompactUnified-Sea-Level-Rise-Projection.pdf (accessed on 23 November 2016).

29. Parris, A.; Bromirski, P.; Burkett, V.; Cayan, D.; Culver, M.; Hall, J.; Horton, R.; Knuuti, K.; Moss, R.; Obeysekera, J.; et al. Global Sea Level Rise Scenarios for the US National Climate Assessment. 2012. Available online: https:/ / scenarios.globalchange.gov/sites/default/files/NOAA_SLR_r3_0.pdf (accessed on 23 November 2016).

30. U.S. Army Corps of Engineers. Incorporating Sea Level Change in Civil Works Programs. 2013. Available online: http://www.corpsclimate.us/docs/EC_Sea_Level_Change_9_July\%2009_signed_version. pdf (accessed on 25 November 2016).

31. Intergovernmental Panel on Climate Change. Climate Change 2013: The Physical Science Basis; Cambridge University Press: Cambridge, UK, 2013.

32. A Global Vulnerability Analysis: Vulnerability Assessment for Population, Coastal Wetlands and Rice Production on a Global Scale. Available online: https:/ / www.researchgate.net/publication/282669649_ A_global_vulnerability_analysis_vulnerability_assessment_for_population_coastal_wetlands_and_rice_ production_on_a_global_scale (accessed on 22 August 2017).

33. Nicholls, R.; Hanson, S.; Brown, S.; Hinkel, J. Economics of Coastal Zone Adaptation to Climate Change; The World Bank Discussion Paper No. 10; Technical Report; World Bank: Washington, DC, USA, 2010.

34. Anthoff, D.; Nicholls, R.J.; Tol, R.S. The economic impact of substantial sea-level rise. Mitig. Adapt. Strateg. Glob. Chang. 2010, 15, 321-335. [CrossRef]

35. Office of Economic and Demographic Research 2016, Miami-Dade County. Available online: http://edr. state.fl.us/content/area-profiles/county / miamidade.pdf (accessed on 8 December 2016).

36. Fankhauser, S. Protection versus retreat: The economic costs of sea-level rise. Environ. Plan. A 1995, 27, 299-319. [CrossRef]

37. Sugiyama, M.; Nicholls, R.J.; Vafeidis, A. Estimating the Economic Cost of Sea-Level Rise; MIT Joint Program on the Science and Policy of Global Change: Cambridge, UK, 2008.

38. Zhang, K. Analysis of non-linear inundation from sea-level rise using LIDAR data: a case study for South Florida. Clim. Chang. 2011, 106, 537-565. [CrossRef]

39. Herald, M. When the Ocean Rolls onto the Roads, King Tide Sends a Message. 2016. Available online: http:/ / www.miamiherald.com/news/local/environment/article108811897.html (accessed on 23 June 2017).

40. Bierbaum, R.; Smith, J.B.; Lee, A.; Blair, M.; Carter, L.; Chapin, F.S.; Wasley, E. A comprehensive review of climate adaptation in the United States: More than before, but less than needed. Mitig. Adapt. Strateg. Glob. Chang. 2013, 18, 361-406. [CrossRef]

41. Fu, X.; Gomaa, M.; Deng, Y.; Peng, Z.R. Adaptation planning for sea level rise: A study of US coastal cities. J. Environ. Plan. Manag. 2017, 60, 249-265. [CrossRef]

42. Song, J.; Fu, X.; Wang, R.; Peng, Z.-R.; Gu, Z. Does planned retreat matter? Investigating land use change under the impacts of flooding induced by sea level rise. Mitig. Adapt. Strateg. Glob. Chang. 2017. [CrossRef]

43. Martinich, J.; Neumann, J.; Ludwig, L.; Jantarasami, L. Risks of sea level rise to disadvantaged communities in the United States. Mitig. Adapt. Strateg. Glob. Chang. 2013, 18, 169-185. [CrossRef]

44. Frazier, T.G.; Wood, N.; Yarnal, B.; Bauer, D.H. Influence of potential sea level rise on societal vulnerability to hurricane storm-surge hazards, Sarasota County, Florida. Appl. Geogr. 2010, 30, 490-505. [CrossRef]

45. Butler, W.H.; Deyle, R.E.; Mutnansky, C. Low-regrets incrementalism: Land use planning adaptation to accelerating sea level rise in Florida's Coastal Communities. J. Plan. Educ. Res. 2016, 36, 319-332. [CrossRef]

(C) 2017 by the authors. Licensee MDPI, Basel, Switzerland. This article is an open access article distributed under the terms and conditions of the Creative Commons Attribution (CC BY) license (http://creativecommons.org/licenses/by/4.0/). 